\title{
The embryonic transcription factor Brachyury blocks cell cycle progression and mediates tumor resistance to conventional antitumor therapies
}

\author{
B Huang ${ }^{1}$, JR Cohen ${ }^{1}$, RI Fernando ${ }^{1}$, DH Hamilton ${ }^{1}$, MT Litzinger ${ }^{1}$, JW Hodge ${ }^{1}$ and C Palena ${ }^{\star, 1}$
}

The T-box transcription factor Brachyury, a molecule frequently detected in human cancers but seldom found in normal adult tissue, has recently been characterized as a driver of the epithelial-to-mesenchymal switch of human carcinomas. In the current investigation, we present data demonstrating that in two different human lung carcinoma models expression of Brachyury strongly correlates with increased in vitro resistance to cytotoxic therapies, such as chemotherapy and radiation. We also demonstrate that chemotherapy treatment in vitro selects for tumor cells with high levels of Brachyury and that the degree of resistance to therapy correlates with the level of Brachyury expression. In vitro and in vivo, human lung carcinoma cells with higher levels of Brachyury divide at slower rates than those with lower levels of Brachyury, a phenomenon associated with marked downregulation of cyclin D1, phosphorylated Rb and CDKN1A (p21). Chromatin immunoprecipitation and luciferase reporter assays revealed that Brachyury binds to a half T-box consensus site located within the promoter region of the p21 gene, indicating a potential mechanism for the observed therapeutic resistance associated with Brachyury expression. Finally, we demonstrate that in vivo treatment of tumor xenografts with chemotherapy results in the selective growth of resistant tumors characterized by high levels of Brachyury expression. Altogether, these results suggest that Brachyury expression may attenuate cell cycle progression, enabling tumor cells to become less susceptible to chemotherapy and radiation in human carcinomas.

Cell Death and Disease (2013) 4, e682; doi:10.1038/cddis.2013.208; published online 20 June 2013

Subject Category: Cancer

The T-box transcription factor Brachyury, an embryonic determinant of mesoderm differentiation, ${ }^{1-3}$ was recently identified as a protein aberrantly expressed in several types of human carcinomas, while being absent in the majority of normal adult tissues. ${ }^{4-6}$ Previous studies from our laboratory demonstrated that high levels of Brachyury in human cancer cells drive an epithelial-to-mesenchymal transition (EMT) in vitro and promote tumor dissemination in vivo. ${ }^{7,8}$ The phenomenon of EMT is thought to be crucial during the progression of carcinomas as it mediates the phenotypic conversion of relatively stationary, polarized epithelial tumor cells into highly migratory and invasive, mesenchymal-like cancer cells. ${ }^{9-12}$ As a result, carcinoma cells undergoing EMT are enabled to initiate the cascade of events leading to establishment of distant metastases. ${ }^{13}$

Recent investigations have also begun to unravel another intriguing aspect of tumor EMT, involving the acquisition of features of cancer stem-like cells and the induction of resistance to cytotoxic therapies. ${ }^{14-16}$ For example, Vega et al. ${ }^{17}$ demonstrated that overexpression of Snail in epithelial cells represses cell cycle progression via downregulation of cyclin D2 and upregulation of CDKN1A (p21) and confers resistance to serum depletion or TNF- $\alpha$ administration by activating the MAPK and PI3K survival pathways. More recently, Gupta et al. ${ }^{18}$ have shown that breast cancer cells induced into an EMT via forced downregulation of epithelial E-cadherin were more resistant than control cells to treatment with paclitaxel and doxorubicin.

In this study, we have investigated whether the EMT process associated with high levels of Brachyury expression in human lung carcinoma cells drives tumor resistance to conventional anticancer modalities, such as chemotherapy and radiation. Our results showed a clear survival benefit for lung cancer cells expressing elevated levels of Brachyury, which significantly resisted the cytocidal effects of such therapeutic agents. In addition, we found that both in vitro and in vivo, human carcinoma cells with high levels of Brachyury grew at significantly lower rates than those with lesser Brachyury levels, a phenomenon we were able to relate to marked downregulation of cyclin D1, phosphorylated Rb $(\mathrm{pRb})$ and p21, a gene previously shown to block EMT and stem cell properties in tumor cells. ${ }^{19}$ Altogether, these results indicate that in addition to being a driver of the epithelialmesenchymal switch, Brachyury expression may also confer a selective growth advantage for tumor cells upon treatment with chemotherapy or radiation in human carcinomas.

\footnotetext{
${ }^{1}$ Laboratory of Tumor Immunology and Biology, Center for Cancer Research, National Cancer Institute, National Institutes of Health, Bethesda, MD, USA ${ }^{*}$ Corresponding author: C Palena, Laboratory of Tumor Immunology and Biology, Center for Cancer Research, National Cancer Institute, National Institutes of Health, 10 Center Drive, Room 8B14, MSC 1750, Bethesda, MD 20892, USA. Tel: 301496 1528; Fax: 301496 2756; E-mail: palenac@mail.nih.gov Keywords: EMT; Brachyury; therapeutic resistance; CDKN1A

Abbreviations: ChIP, chromatin immunoprecipitation; EMT, epithelial-to-mesenchymal transition; DDR, DNA damage response; HBSS, Hank's balanced salt solution; MET, mesenchymal-to-epithelial transition; MTT, 3-4,5-dimethylthiozol-2, 5-diphenyl-tetrazolium bromide; shRNA, short hairpin RNA; siRNA, small interfering RNA Received 28.11.12; revised 18.4.13; accepted 14.5.13; Edited by G Ciliberto
} 


\section{Results}

Brachyury overexpression drives an epithelialmesenchymal switch in human carcinomas and decreases tumor susceptibility to cytotoxic modalities. To study the effect of Brachyury expression in lung carcinoma cells, A549 epithelial cells characterized by low levels of Brachyury were stably transfected with a plasmid encoding the full-length human Brachyury protein (pBrachyury) or a control pCMV vector. In agreement with the previously demonstrated role of Brachyury as an inducer of a mesenchymal-like phenotype in carcinoma cells, ${ }^{7}$ this genetic manipulation of A549 cells significantly decreased the expression of the epithelial proteins E-cadherin and plakoglobin, while simultaneously increasing expression of the mesenchymal proteins fibronectin and vimentin (Figures $1 \mathrm{a}$ and b). In addition, overexpression of Brachyury in A549 cells resulted in enhanced expression of mRNAs encoding for the EMT transcription factors Snail and Slug (Figure 1c) and significantly enhanced tumor invasiveness in vitro, as compared with control A549 pCMV cells (Figure 1d). To investigate whether Brachyury-mediated EMT in A549 cells could impact their ability to withstand several of the therapeutics commonly utilized for the clinical management of lung cancer, cells were exposed to various clinically relevant doses of docetaxel, cisplatin and vinorelbine. ${ }^{20-22}$ As shown in Figure 1e, Brachyury overexpression led to a significant survival advantage for the A549 cells; approximately twice as many A549 pBrachyury cells survived treatment with docetaxel, cisplatin or the combination cisplatin plus vinorelbine than A549 pCMV cells. In addition to chemotherapy, radiation therapy is also a main therapeutic option for treatment of lung cancer. ${ }^{23}$ Overexpression of Brachyury in A549 cells resulted in enhanced resistance to gamma radiation, at doses ranging from 2 to $8 \mathrm{~Gy}$, as compared with control A549 pCMV cells (Figure 1f).

In additional experiments, the suppression of Brachyury expression in the mesenchymal $\mathrm{H} 460$ lung carcinoma cells ${ }^{7}$ by stable transfection with two different Brachyury-targeting short hairpin RNA (shRNA) constructs resulted in enhanced expression of epithelial plakoglobin (Figure 2a) and decreased expression of mesenchymal fibronectin and vimentin proteins (Figures $2 a$ and b). Expression of E-cadherin was not detected in H460 control.shRNA cells and its a

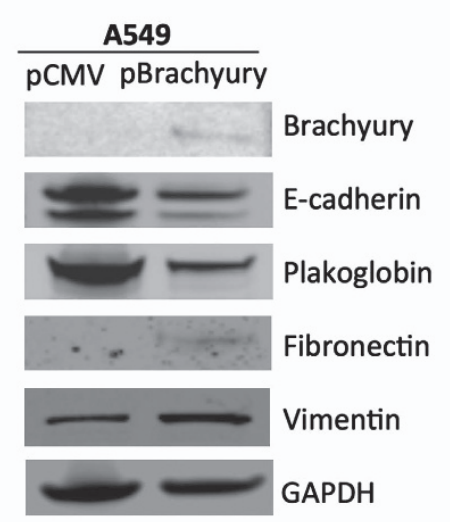

b
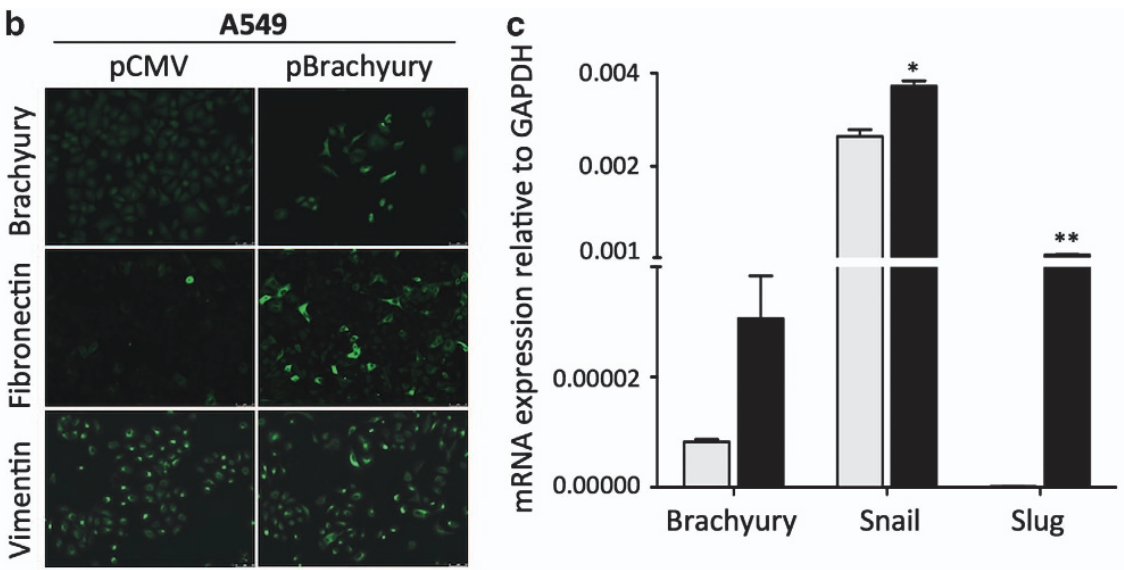

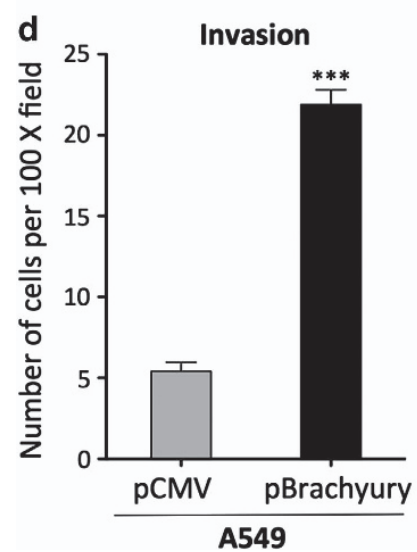

e
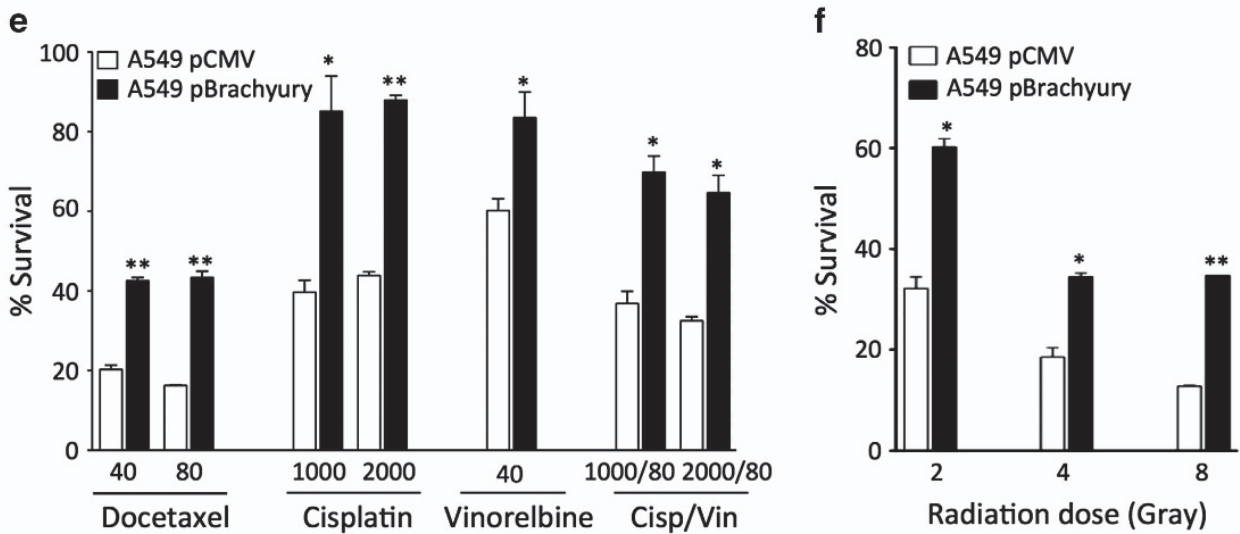

Figure 1 Overexpression of Brachyury is associated with EMT and increased resistance to chemotherapy and radiation. A549 cells stably transfected with an empty vector (pCMV) or a Brachyury-encoding vector (pBrachyury) were analyzed for expression of Brachyury, E-cadherin, plakoglobin, fibronectin and vimentin by western blot (a) or by indirect immunofluorescence staining (b) for Brachyury, fibronectin and vimentin. (Magnification $\times 40$ ). (c) cDNA generated from A549 pCMV (gray bars) and pBrachyury cells (black bars) was analyzed for expression of Brachyury, Snail and Slug by quantitative real-time PCR, as compared with GAPDH. (d) Invasion assays were performed using A549 pCMV, as compared with A549 pBrachyury cells. Indicated tumor cells were treated with various doses of (e) chemotherapy (ng/ml) or (f) gamma radiation (Gy) and assayed after 2 or 5 days of culture, respectively, for survival in comparison with untreated cells. Assays were performed in triplicate or quadruplicate; error bars correspond to S.E.M. Data shown are representative of at least two separate experiments $\left({ }^{*} P<0.05,{ }^{* *} P<0.01\right)$ 
expression was not reconstituted after Brachyury inhibition. In agreement with the results observed with A549 cells, Brachyury inhibition in $\mathrm{H} 460$ cells concomitantly downregulated the expression of Snail and Slug mRNA (Figure 2c) and had a profound, negative impact on the ability of $\mathrm{H} 460$ cells to invade the extracellular matrix, in vitro (Figure $2 \mathrm{~d}$ ). As a result of Brachyury inhibition, the survival of $\mathrm{H} 460$ cells was significantly decreased after treatment with various doses of all chemotherapeutics tested, compared with H460 control.shRNA cells (Figure 2e). Similarly, it was found that significantly fewer $\mathrm{H} 460$ cells inhibited for Brachyury expression survived radiotherapy as compared with control cells (Figure 2f).

These results, together with our previous observations, ${ }^{7,8}$ indicated that elevated expression of Brachyury in human lung carcinoma cells is associated with the acquisition of a mesenchymal-like phenotype and the gain of resistance to cytotoxic agents.

Chemotherapy-resistant tumor cells express high levels of Brachyury. To investigate whether exposure of tumor cells to chemotherapy might select cells with spontaneously high levels of Brachyury, untransfected A549 cells were incubated for $6 \mathrm{~h}$ in culture with docetaxel or a combination of cisplatin/vinorelbine, and subsequently propagated in the absence of chemotherapeutics. Following three additional cycles of chemotherapy selection and recovery, immunofluourescence (Figure 3a) and western blot analysis (Figure 3b) showed substantially elevated expression of Brachyury in surviving A549 cells compared with untreated cells, which was accompanied by the gain of the mesenchymal markers vimentin and fibronectin (Figure 3a). These results led us to hypothesize that in vivo treatment of a tumor with cytotoxic therapies could also enrich for a population of cells with high levels of Brachyury. To confirm this hypothesis, xenografts of untransfected $\mathrm{H} 460$ cells were treated with either docetaxel or Hank's balanced salt solution (HBSS) as described in Materials and Methods section. Immunohistochemistry analysis of Brachyury expression in excised tumors revealed that $\mathrm{H} 460$ tumor cells that survived docetaxel treatment had markedly higher levels of Brachyury as compared with HBSS-treated tumors (Figure 3c). Based a

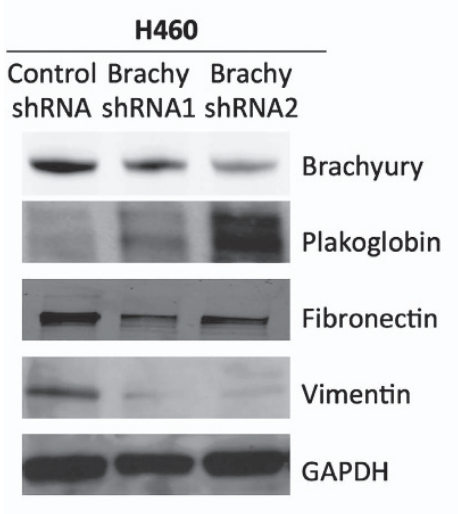

b
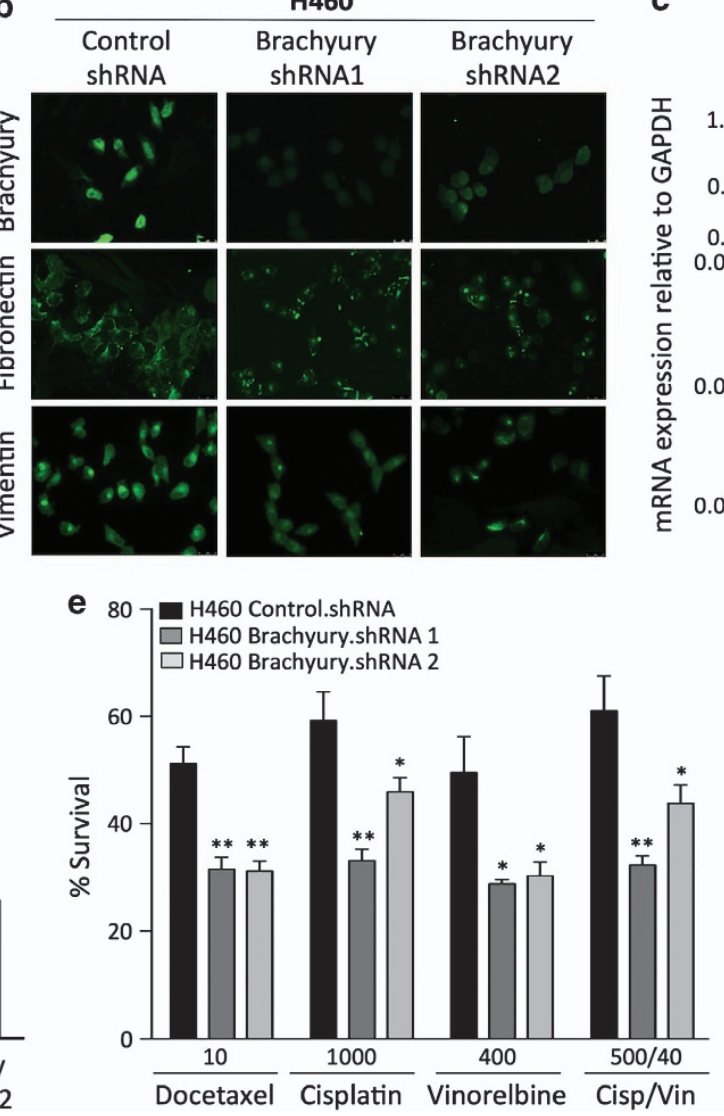

C
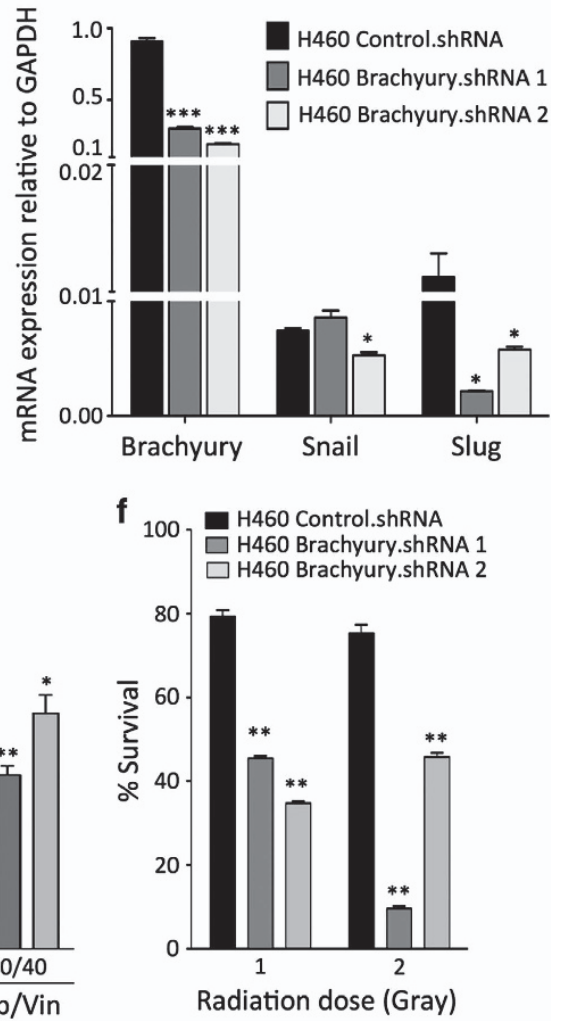

Figure 2 Inhibition of Brachyury expression is associated with a mesenchymal-to-epithelial transition (MET) and decreased resistance to chemotherapy and radiation. H460 cells were stably transfected with vectors encoding for a nonspecific control shRNA (Control), or either of two different Brachyury-specific shRNAs (shRNA1 and shRNA2). Protein lysates collected from these cells were analyzed for expression of Brachyury, plakoglobin, fibronectin and vimentin by western blot (a) or by indirect immunofluorescence staining (b) for Brachyury, fibronectin, and vimentin. (Magnification $\times 40$ ). (c) cDNA generated from H460 control.shRNA or Brachyury.shRNA-1 and -2 were analyzed for expression of Brachyury, Snail and Slug by quantitative real-time PCR, as compared with GAPDH. (d) Invasion assays were also performed with these cells. Indicated tumor cells were treated with various doses of chemotherapy $(\mathrm{ng} / \mathrm{ml})(\mathbf{e})$ or gamma radiation (Gy) (f) and assayed after 5 days culture for survival in comparison with untreated cells. Assays were performed in triplicate or quadruplicate; error bars correspond to S.E.M. Data shown are representative of at least two separate experiments $\left({ }^{\star} P<0.05,{ }^{* *} P<0.01,{ }^{* \star *} P<0.001\right)$ 
a
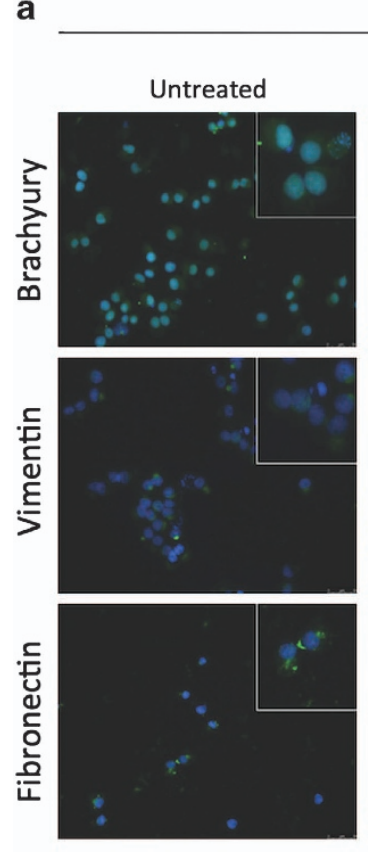

b

\section{A549}

\section{Docetaxel} $1 \mathrm{ng} / \mathrm{ml}$
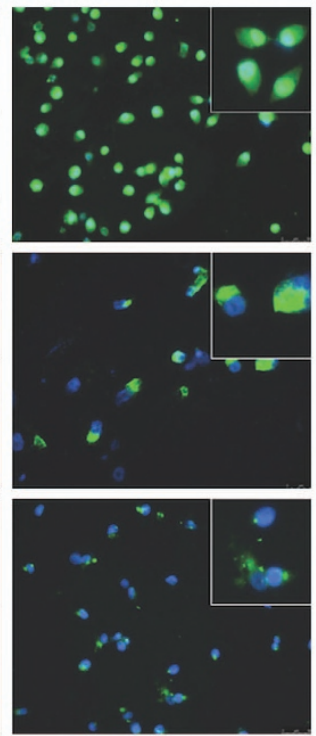

Cisplatin /Vinorelbine $500 / 40 \mathrm{ng} / \mathrm{ml}$
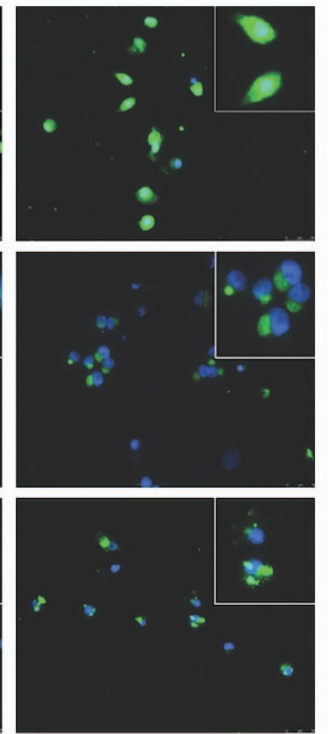

A549

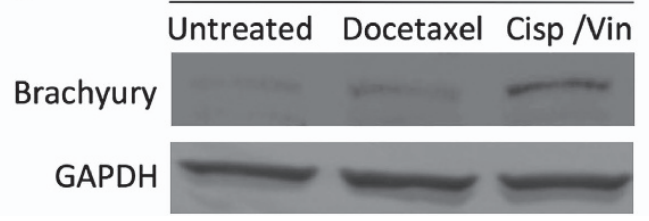

C
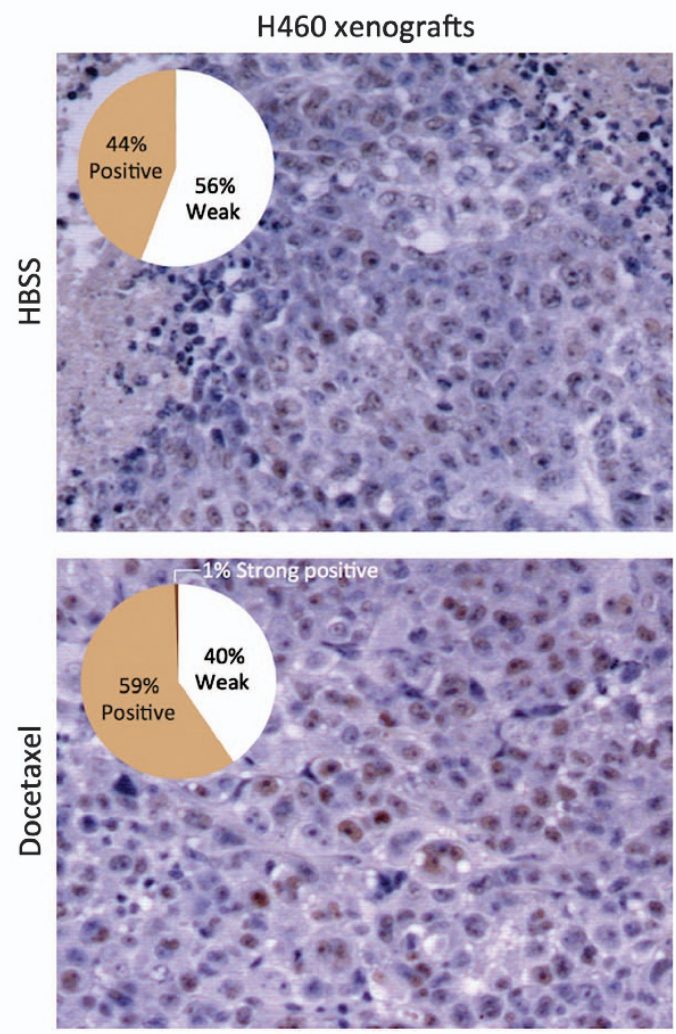

Figure 3 Tumor cells with high levels of Brachyury are selected by chemotherapy. (a) Untransfected A549 cells were selected by successive rounds of chemotherapy treatment in vitro; at the end of the fourth cycle, surviving cells were harvested, attached to glass coverslips and analyzed by indirect immunofluorescence for Brachyury, vimentin and fibronectin (green fluorescence). Blue fluorescence corresponds to DAPI-stained nuclei (magnification $\times 40$ ). Detailed images of stained cells are shown in the insets. (b) Protein lysates obtained from A549 cells surviving four cycles of the indicated chemotherapy treatments were analyzed for Brachyury expression by western blot. (c) Nude mice bearing xenografts of $\mathrm{H} 460$ tumor cells were treated with three cycles of intraperitoneal docetaxel therapy or HBSS; tumors were collected and stained for Brachyury-specific immunohistochemistry. Shown are representative pictures from each group ( $n=3$ mice per group; original magnification $\times 10$ ). Quantification of positive signals was conducted by using the Aperio ImageScope Viewer software; graphs indicate the percentage of positive pixels, as described in the Materials and Methods section

on these results, we then investigated whether the resistance associated with Brachyury is directly related to its magnitude of expression. Several single-cell clones were isolated from the bulk A549 pBrachyury population, and six different clonal populations possessing a diversity of Brachyury expression (Figure $4 \mathrm{a}$ ) were chosen for detailed examination of their growth kinetics (Figure 4b) and the relationship between Brachyury and susceptibility to chemotherapy (Figure 4c). Survival assays revealed a strong positive correlation between the level of Brachyury and the survival of the tumor cells in response to docetaxel $(r=0.895)$, cisplatin $(r=0.862)$, vinorelbine $(r=0.881)$ and the combination of cisplatin and vinorelbine $(r=0.873)$. These results further supported the notion that the observed tumor resistance might be directly relatable to the amount of Brachyury the cells were expressing. In addition, the observations seemed to imply that the phenomenon of elevated Brachyury in the surviving non-clonal chemotherapy-treated cells (as described in Figures $3 a-c)$ was due to selection and enrichment of spontaneously Brachyury-high cells, rather than an induction of Brachyury in response to treatment.
Brachyury expression impairs cell cycle progression. The impact of Brachyury overexpression in tumor cell proliferation and cell cycle progression were also investigated. As shown in Figure 5, forced overexpression of Brachyury in A549 cells significantly decreased cell proliferation (Figure 5a), while its silencing in $\mathrm{H} 460$ cells led to significantly increased growth (Figure 5b). Similarly, the proliferation analysis of the A549 pBrachyury clones (Figure $4 \mathrm{~b}$ ) revealed a strong inverse correlative trend $(r=-0.807)$ between their growth and the expression of Brachyury. Experiments conducted with xenografts of $\mathrm{H} 460$ cells in nude mice also demonstrated that $\mathrm{H} 460$ cells silenced for the expression of Brachyury (H460 Brachyury.shRNA2) grew at significantly higher rates than $\mathrm{H} 460$ control.shRNA cells (Figure $5 \mathrm{c}$ ), paralleling the results observed in vitro.

Having shown that high levels of Brachyury reduce tumor cell proliferation, its effect on cell cycle distribution was also investigated by propidium iodide staining of cellular DNA content. Tumor cells with high levels of Brachyury (H460 control.shRNA) demonstrated higher G1 fraction 

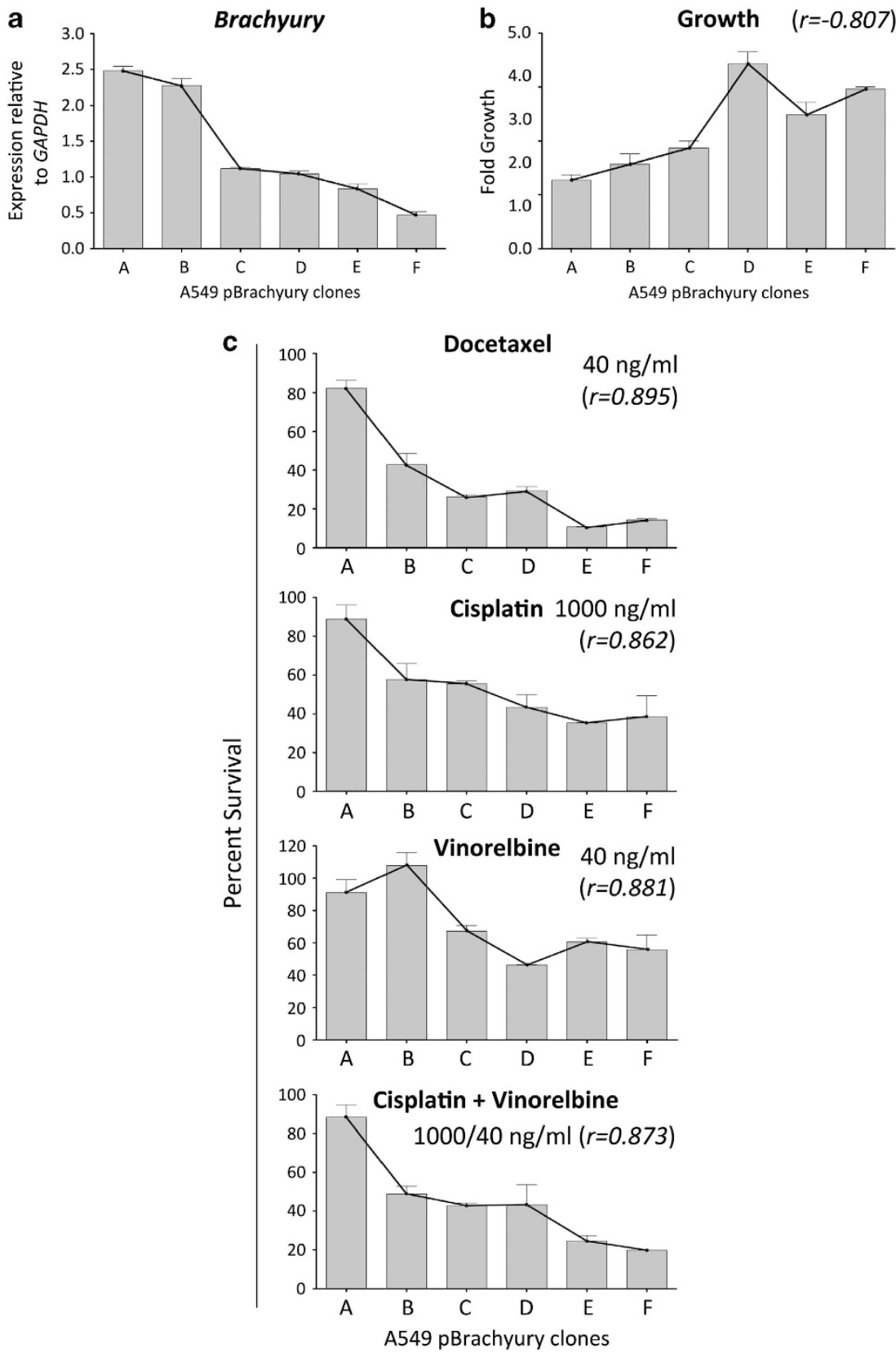

Figure 4 Correlation of Brachyury levels with survival to chemotherapy. A549 pBrachyury single-cell clones (designated with indicated letters) were quantified for Brachyury expression by real-time PCR (a), and (b) evaluated for growth over a 5-day period. (c) Survival of individual clones in response to treatment with indicated doses of chemotherapeutics; numbers in parentheses indicate the Pearson's correlation coefficient calculated in relation to Brachyury expression. All chemotherapy assays were performed in triplicate or quadruplicate, error bars denote S.E.M. Growth data shown are pooled results of at least two separate experiments \pm S.E.M.

$(50 \%$, Figure $5 \mathrm{~d})$ than tumor cells with low Brachyury expression (H460 Brachyury.shRNA2, 33.6\%). A higher G2/ $M$ fraction was observed in Brachyury-inhibited cells, thus corroborating enhanced cell cycle progression in these cells. A detailed analysis of cell cycle regulatory proteins was then conducted with various isogenic tumor cell pairs expressing various levels of Brachyury. Synchronized cultures of A549 pBrachyury cells induced to enter the cell cycle by addition of serum (Figure 6a) expressed markedly lower levels of $p R b$, cyclin D1 and p21 than the corresponding cultures of A549 pCMV cells. In addition, isogenic $\mathrm{H} 460$ cell lines showed that suppression of Brachyury led to an increase in the levels of cyclin D1 and p21 (Figure 6b). Differential expression of pRb and p21 were also observed in two populations of $\mathrm{H} 460$ cells derived from single-cell clones (designated $\mathrm{H} 460$ clone 1 and 2, Figure 6c); H460 clone 1 cells, characterized by higher levels of Brachyury, showed diminished pRb and p21 levels than those of H460 clone 2, which expressed lower levels of Brachyury.

Role of Brachyury-mediated p21 repression. The positive association observed between p21 expression and tumor cell proliferation appeared intriguing, as p21 has been previously 

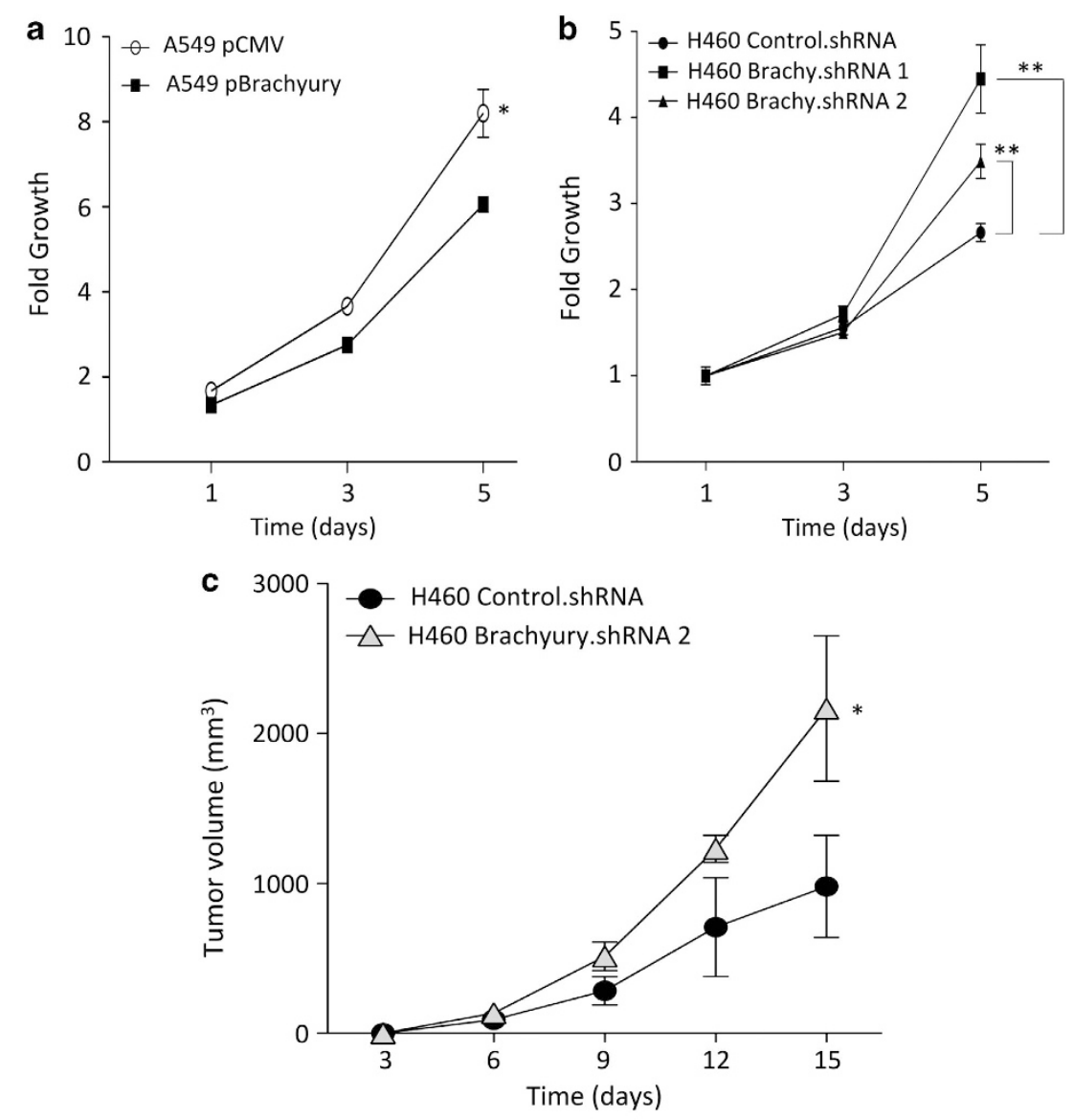

d

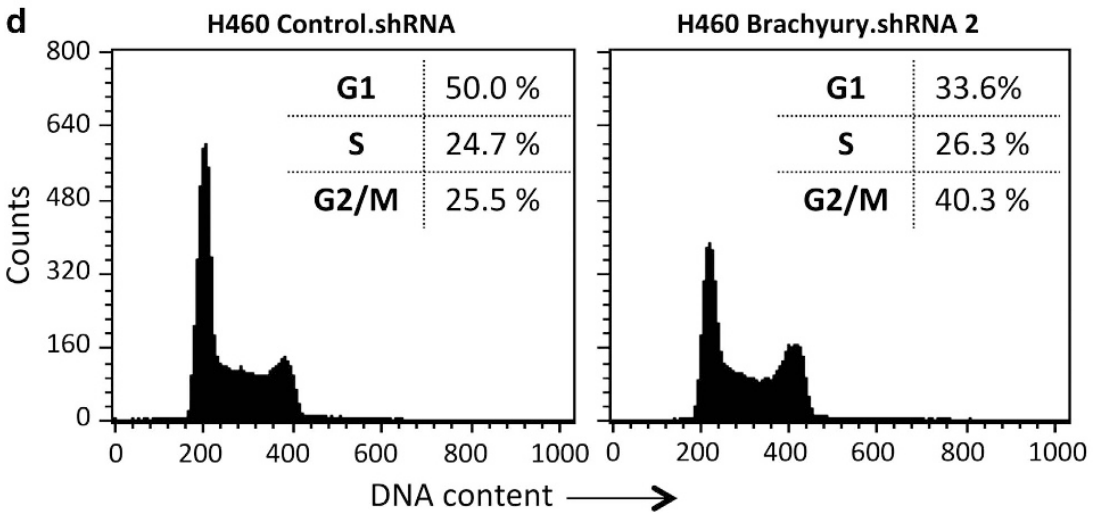

Figure 5 Overexpression of Brachyury attenuates tumor cell proliferation and impairs cell cycle progression. (a and $\mathbf{b}$ ) Growth kinetics of indicated tumor cell lines analyzed by the MTT assay. (c) In vivo growth of H460 control.shRNA cells compared with H460 Brachyury.shRNA 2 cells determined over a 15-day period. Error bars correspond to S.E.M. for triplicate or quadruplicate measurements $\left({ }^{*} P<0.05\right.$, $\left.{ }^{* *} P<0.01\right)$. (d) Flow cytometric cell cycle analysis of H460 control.shRNA and H460 Brachyury.shRNA2 was performed by propidium iodide DNA staining

described as a potent inhibitor of cyclin-dependent kinases. ${ }^{24}$ Other studies, however, have shown that p21 could also favor cell cycle progression by acting as a major adaptor protein that assembles cyclin D1/cdk4 complexes, targeting them into the nucleus and favoring cyclin D1-associated kinase activity. ${ }^{25}$ Based on the positive role of p21 in cell cycle progression, we hypothesized that reduced levels of p21 in tumor cells with high levels of Brachyury could lead to diminished proliferation. In order to investigate this possibility, H460 tumor cells were stably transfected with a vector encoding the full-length human p21 gene or a control vector. As shown in Figure $6 \mathrm{~d}$, forced upregulation of p21 expression in the presence of high endogenous levels of Brachyury was sufficient to reconstitute $\mathrm{pRb}$ and markedly increase tumor cell proliferation (Figure 6e). Our results thus suggested that reduction of p21 might be responsible for the low proliferation characteristic of Brachyury-high tumor cells, potentially leading to the decreased tumor susceptibility to cytotoxic therapies. Supporting this hypothesis, it was observed that increasing p21 levels alone in H460 cells was sufficient to 


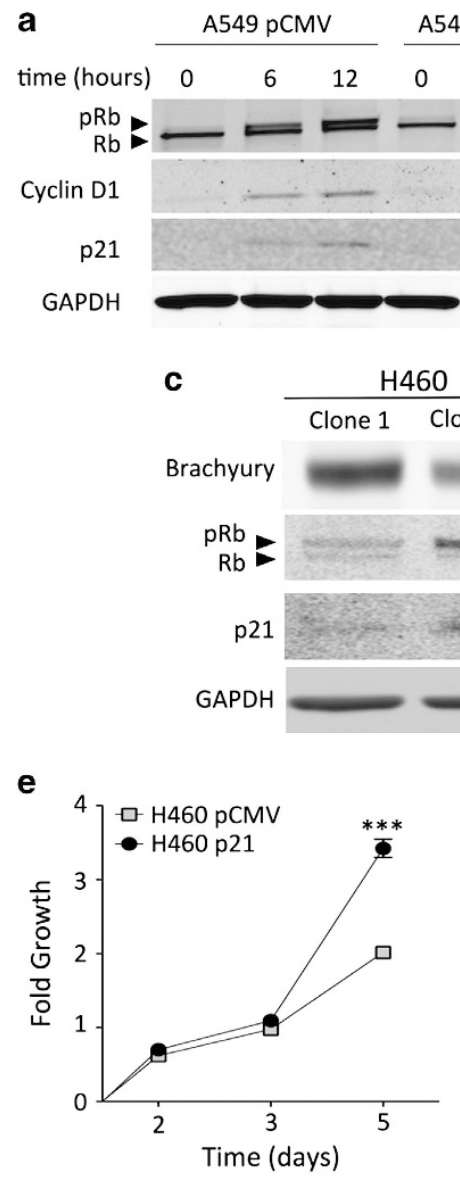
A549 pBrachyury
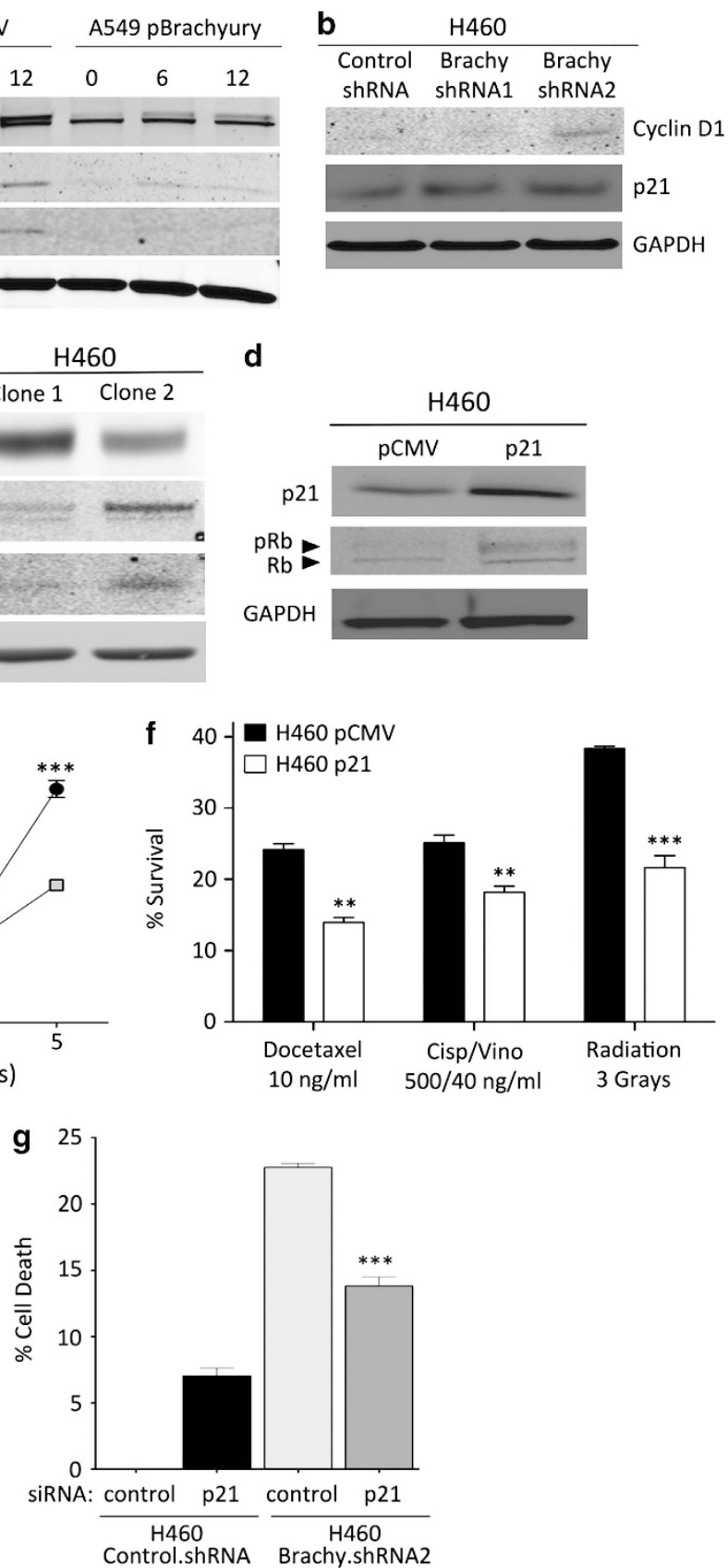

Figure 6 Brachyury modulates expression of cell cycle regulatory proteins. Western blot analysis of Brachyury and the cell cycle regulatory proteins Rb, cyclin D1 and p21 was performed using (a) the A549 tumor cell pair at indicated times after release from cell cycle arrest by serum starvation or (b) asynchronous cultures of H460 control versus Brachyury shRNA-1 and -2 cells. (c) Two tumor cell lines derived from single-cell cloning of $\mathrm{H} 460$ cells were analyzed for expression of Brachyury in relation to Rb and p21. (d) H460 cells transfected with p21 expression vector or pCMV control were analyzed for p21 and Rb expression by western blot and (e) growth kinetics over a 5-day period. (f) Indicated cells were treated with cytotoxic therapies and assayed for survival in comparison with untreated cells. (g) The $\mathrm{H} 460$ cell pair transfected with a pool of nonspecific control siRNA or p21-specific siRNAs was treated with $\gamma$-radiation (1 Gy) and evaluated for cell death by using CellTiter-Glo (Promega). $\left({ }^{\star \star} P<0.01 ;{ }^{* \star \star} P<0.001\right)$

significantly increase their susceptibility to chemotherapy and radiation (Figure 6f), and that silencing of p21 in Brachyury-low (H460 Brachyury.shRNA2) cells was able to decrease tumor susceptibility in response to radiation (Figure 6g).

Examination of the human p21 gene promoter sequence for the presence of a consensus T-box-binding element (5'-ATTTCACACCTAGGTGTGAAATT-3') revealed a half-site
(5'-AGGTGTGA-3') at position - 14 relative to the transcription initiation site (Figure 7a). Chromatin immunoprecipitation (ChIP) analysis with H460 control.shRNA and A549 pBrachyury cells indicated that Brachyury directly binds the promoter of p21, a phenomenon that was not observed with concurrent ChIP analysis of $\mathrm{H} 460$ Brachyury.shRNA2 cells silenced for expression of Brachyury (Figure 7a). To investigate whether reduced levels of p21 in Brachyury-high cells was a result of 
a

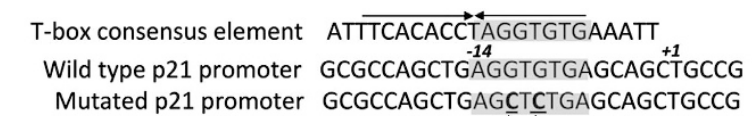
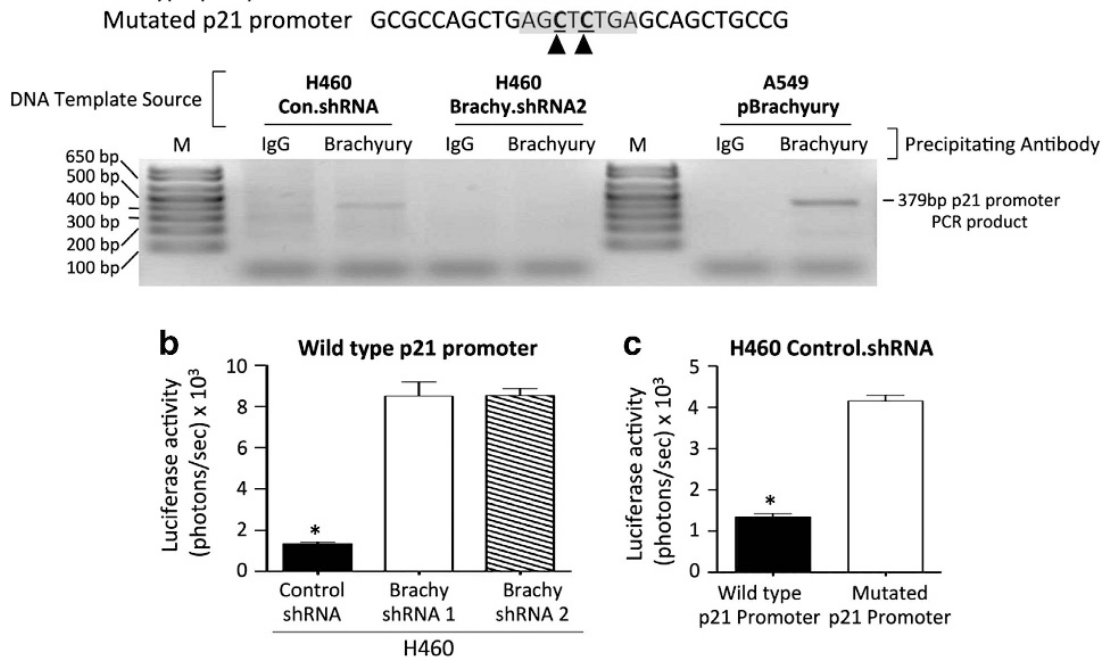

d
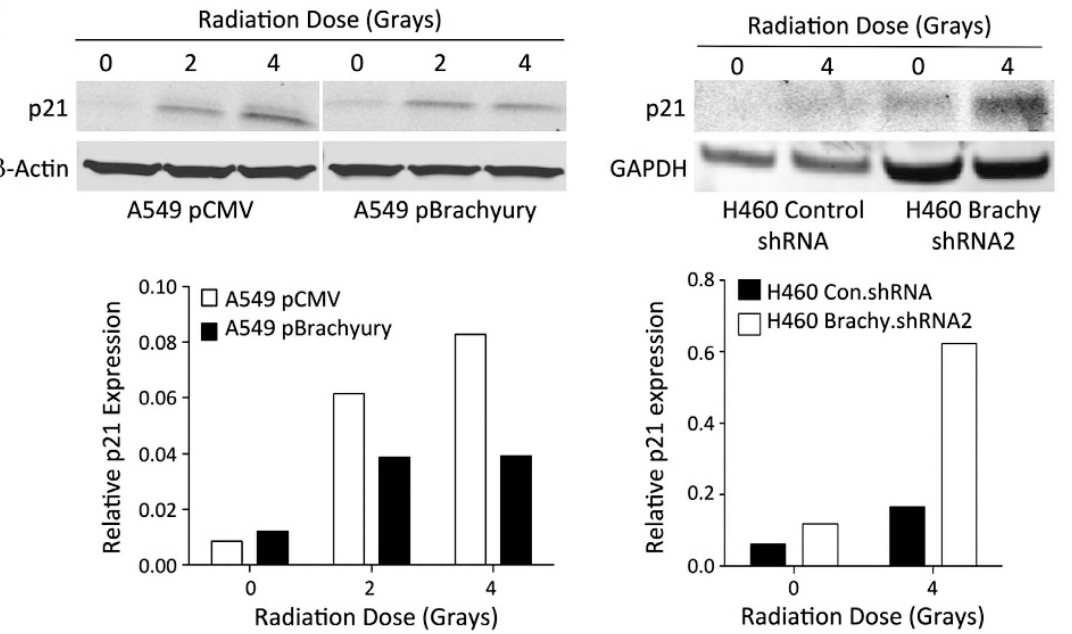

Figure 7 Brachyury drives repression of p21. (a) A ChIP assay was employed utilizing control IgG versus anti-Brachyury antibody with template DNA obtained from indicated cells. Shown at the top is the T-box palindromic consensus element juxtaposed with the half-binding site (shaded) located in the human p21 promoter (wild type), and a mutated p21 promoter containing point mutations in the T-box-binding site (denoted by arrowheads). Depicted below is the gel electrophoresis of PCR products amplified from the indicated immunoprecipitated DNA template sources using p21 promoter-specific primers. M corresponds to the DNA ladder. (b) Luciferase reporter assay was used to analyze $\mathrm{H} 460$ cells utilizing a wild-type p21 promoter driving the expression of the luciferase gene. (c) Luciferase reporter assay with H460 control.shRNA cells utilizing a wild-type versus mutated human p21 promoter driving the expression of the luciferase gene. Values shown represent the average of two technical replicates corrected for background \pm S.E.M. ( ${ }^{*} P<0.05$ ). (d) Synchronized A549 pCMV and pBrachyury cells or asynchronous H460 control.shRNA and H460 Brachyury.shRNA2 were treated with indicated doses of radiation; cells collected after $24 \mathrm{~h}$ were analyzed for p21 induction by western blot. Intensity of p21 detection was quantitated and compared against $\beta$-actin or GAPDH (bottom panels)

transcriptional silencing, $\mathrm{H} 460$ control.shRNA versus $\mathrm{H} 460$ Brachyury.shRNA-1, -2 cells were transiently transfected with a reporter construct containing the luciferase gene under the control of a 969-bp fragment of the human p21 promoter ('wildtype p21 promoter', positions -891 to +78 ) (Figure 7a). As shown in Figure $7 \mathrm{~b}$, the p21 reporter activity was significantly enhanced in $\mathrm{H} 460$ cells silenced for expression of Brachyury as compared with control cells, hence indicating that Brachyury directly or indirectly represses p21 transcription in these cells. By introducing two mutations in the T-box half-binding site of the p21 promoter-reporter vector ('mutated p21 promoter'; Figure 7a), it was demonstrated that binding of Brachyury is required for repression of p21 transcriptional activity (Figure 7c), because mutation of the T-box half-binding site enhanced the transcriptional activity of the $\mathrm{p} 21$ promoter in H460 control.shRNA cells.

Deficient DNA damage response (DDR) in Brachyuryhigh tumor cells. Owing to the central role of the p21 protein in the p53-mediated cell cycle arrest following genotoxic stress, we have also investigated whether upregulation of $\mathrm{p} 21$ expression in response to $\gamma$-radiation could be compromised in tumor cells with high levels of Brachyury. As shown in Figure 7d, irradiation of A549 pCMV cells resulted in up to ninefold upregulation of p21 protein levels while only approximately fourfold upregulation was achieved in 
irradiated A549 pBrachyury cells. Similarly, irradiation of H460 Brachyury.shRNA2 cells resulted in a 5.3-fold induction of p21 expression while a 2.7-fold upregulation was observed in Brachyury-high $\mathrm{H} 460$ control.shRNA cells. These results suggested that high levels of Brachyury could also hinder the tumor response to DNA damage.

\section{Discussion}

The studies reported here demonstrate for the first time a link between the transcription factor Brachyury and resistance to conventional therapies in human carcinomas. High levels of Brachyury expression in human lung cancer cells are shown here to impair cell cycle progression and to decrease tumor susceptibility to various chemotherapies and radiation. Brachyury is an embryonic, tissue-specific transcription factor of the T-box family, essential for mesoderm differentiation during vertebrate development. ${ }^{26-28}$ Our previous studies have shown that Brachyury is aberrantly re-expressed in multiple types of human carcinomas and that high levels of Brachyury expression drive the phenotypic conversion of tumor cells into mesenchymal-like cancer cells. ${ }^{7,29}$ Although the link between the acquisition of mesenchymal-like features and the resistance of carcinoma cells to cytotoxic agents has been demonstrated in some experimental models, ${ }^{14,15,30}$ we are unaware of reports associating the expression of Brachyury with tumor resistance to anticancer therapeutics.

A potential mechanism by which Brachyury could impart tumor resistance to cytotoxic treatments is described here, relating to the decreased proliferation of cancer cells with high levels of this transcription factor. A strong inverse correlation was shown between the levels of Brachyury in single-cellderived lung cancer populations and their growth rate in vitro. In addition, xenografts of Brachyury-high tumors grew at significantly lower rates than those with lesser Brachyury levels. These results thus suggested that expression of Brachyury in cancer cells might mediate a reciprocal switching between cell proliferation and the establishment of a molecular program that culminates with the acquisition of a mesenchymal-like, highly migratory and invasive phenotype. In support to this assumption, a similar phenomenon is described during embryonic development, where the area of Brachyury-expressing mesoderm progenitor cells in the gastrulating rabbit embryo has been described as an area of low proliferative and highly migratory activity. ${ }^{31}$ Although tumor proliferation seems to be logically required for a tumor to progress and multiple studies associate markers of proliferation such as Ki-67, mitotic index and others with poor prognosis, $^{32}$ invasiveness and proliferation appear to be mutually exclusive. For example, this phenomenon was demonstrated with invasive breast cancer cells isolated in vivo after chemotactic attraction that showed activation of gene expression programs related to motility and invasiveness in the absence of proliferation or apoptosis. ${ }^{33}$

Inhibition of cell cycle mediated by Brachyury overexpression is shown here to associate with decreased $\mathrm{pRb}$ and cyclin D1 expression, results that are in agreement with the attenuation of cell cycle mediated by members of the Snail/Slug and ZEB1/SIP1 families, which impair G1/S phase progression via repression of cyclin $D$ and $R b$ hypophosphorylation. ${ }^{17,34}$ Unlike Snail, which blocks G1/S transition via upregulation of p21 expression, in our experimental systems we have observed a marked reduction, rather than overexpression, of p21 in Brachyury-high tumor cells. Although this expression pattern may appear to contradict the role of p21 as an inhibitor of cell cycle, ${ }^{24}$ we have demonstrated here that upregulation of p21 in tumor cells with high levels of Brachyury was sufficient to release cell cycle and to promote cell proliferation, an effect that sensitizes cancer cells to chemotherapy and radiation treatment. Therefore, the role of p21 in our experimental systems seems to be that of promoting, rather than blocking, cell cycle progression. Our results evoke the role of p21 during Notch activation in endothelial cells where inhibition of cell cycle progression is due to the repression of p21 expression which, in turn, prevents entrance of cyclin D/cdk4 into the nucleus and delays phosphorylation of $\mathrm{Rb} .^{35}$ We postulate that a similar mechanism might be involved in the inhibition of cell cycle mediated by p21 downregulation in Brachyury-high tumor cells.

The mechanism by which p21 is downregulated in the presence of high levels of Brachyrury was also investigated here. We have shown that Brachyury directly binds to the promoter of p21 and that the transcriptional activity of this promoter is impaired in the presence of high levels of Brachyury. Although Brachyury binding to the p21 promoter is shown here to be required for the transcriptional repression of p21, Brachyury has been previously described as an activator of transcription. Therefore, Brachyury-mediated repression of p21 may necessitate cooperation with additional transcriptional repressors or cofactors. This was the case with E-cadherin repression mediated by Brachyury upregulation in pancreatic tumor cells, where it was shown that Brachyury binding to the E-cadherin promoter was necessary to fully repress its expression, an effect that was dependent on a Brachyury/Slug cooperation. $^{7}$

Upregulation of p21 protein expression is a major event associated with the p53-mediated DDR triggered after a cell's exposure to genotoxic agents, including $\gamma$-radiation and chemotherapies. $^{36}$ Absence of $\mathrm{p} 21$ has been previously shown to abrogate p53-mediated cell cycle arrest in response to DNA damage. ${ }^{37,38}$ Our results showed that lung carcinoma cells with high levels of Brachyury expression inefficiently upregulate p21 in response to $\gamma$-radiation treatment as compared with control cells. By suppressing p21 upregulation, tumor cells with high levels of Brachyury could bypass mechanisms of senescence induced by $\mathrm{p} 21$ and continue to proliferate even in the presence of irreparable DNA damage, a phenomenon that could promote accumulation of genomic alterations and genomic instability.

Interestingly, recent studies have also shown that p21 is able to attenuate Ras- and c-Myc-dependent EMT and expression of stem cell-like genes in breast cancer cell lines. It is therefore conceivable that in our system, the repression of p21 that takes place during Brachyury upregulation in tumor cells could also contribute to the maintenance of the mesenchymal characteristic of cancer cells with high levels of Brachyury. ${ }^{19}$

Several reports have demonstrated a link between EMT and properties of stem cells. ${ }^{18,39,40}$ Mani et al. ${ }^{39}$ reported that 
mammary epithelial cells acquire a pattern of phenotypic markers typical of stem cells and sphere-forming ability following induction of EMT. In addition, studies in pancreatic cancer found that therapy-resistant tumor cells had concomitantly acquired markers associated with stem-like cells and changes related to EMT, such as vimentin upregulation and E-cadherin downregulation. ${ }^{41}$ Intriguingly, one point of intersection connecting the concepts of EMT, stem-like state, and therapy resistance, is that of proliferative restraint. As conventional cancer therapies such as chemotherapy and radiation target rapidly proliferating cells and require cell cycle processes to trigger apoptosis, it seems likely that inhibition of cell cycle could have the benefit of allowing tumor cells to initiate repair mechanisms, potentially preventing cytotoxicity.

A recent publication showed that Brachyury drives the acquisition of a stem-like phenotype in colon carcinoma cells. ${ }^{42}$ Although we have not evaluated whether Brachyury expression associates with features of stem cells in lung cancer, we have demonstrated here that lung carcinoma cells with high levels of Brachyury could be selected from a heterogenous tumor population as a result of exposure to cytotoxic agents, a phenomenon frequently observed with stem-like cells. This result, together with our previous studies on the role of Brachyury in the epithelial-mesenchymal switch and metastasis led us to hypothesize that the development of novel therapies specifically aimed at eliminating Brachyurypositive tumor cells could help reduce the occurrence of metastasis and/or alleviate therapeutic resistance in human cancer. One possible strategy to eliminate tumor cells with high Brachyury levels that are otherwise resistant to conventional therapies is via immunotherapies with Brachyury-based vaccine platforms. Supporting this proposal, we previously reported on the expansion of Brachyury-specific $T$ cells from the blood of cancer patients using Brachyury-specific peptides, and have shown that those T cells could lyse Brachyuryexpressing tumor cells. ${ }^{4}$ A Brachyury-based cancer vaccine has been developed that is currently undergoing phase I clinical testing in patients with carcinomas. If effective, cancer vaccines directed against Brachyury could circumvent the problem of resistance to chemotherapy and radiation and help decrease the rate of metastasis of human carcinomas characterized by overexpression of Brachyury.

\section{Materials and Methods \\ Cell lines and culture. The human lung carcinoma lines A549 and H460 were purchased from the American Type Culture Collection (ATCC, Rockville, MD, USA) and propagated as recommended. Transfected A549 cells were selected with $500 \mu \mathrm{g} / \mathrm{ml}$ G418 (Invitrogen Corp., Carlsbad, CA, USA); transfected H460 cells were selected with $1 \mu \mathrm{g} / \mathrm{ml}$ puromycin (Sigma-Aldrich, St. Louis, MO, USA).}

Plasmids and small interfering RNA (siRNA). The full-length human Brachyury construct (pCMV-Neo-Brachyury, accession number NM_003181.2), a p21 expression vector (accession number NM_078467.1) and empty-vector control (pCMV-Neo) were purchased from Origene Technologies Inc. (Rockville, MD, USA). The Brachyury.shRNA1, Brachyury.shRNA2 and control.shRNA vectors used to transfect $\mathrm{H} 460$ cells were purchased from Sigma-Aldrich. A pool of p21-specific and a non-targeting siRNA were obtained from Thermo Fisher Scientific (Waltham, MA, USA).

Real-time PCR. Analysis of gene expression by real-time PCR was conducted as previously described, ${ }^{7}$ with TaqMan human gene expression assays for Brachyury, Snail, Slug and GAPDH (Applied Biosystems, Carlsbad, CA, USA). All reactions were performed in triplicate; data shown are representative averages, with standard error.

Cell invasion assays. Blind Well Chambers (Neuro Probe Inc., Gaithersburg, MD, USA) with $10 \mu \mathrm{m}$ pore polycarbonate filters coated with Matrigel (BD Biosciences, San Jose, CA, USA) were used. RPMI-1640 supplemented with $10 \%$ FBS was added to the lower chambers; cells $\left(1 \times 10^{5}\right)$ were added in serumfree medium onto the upper chambers. After $24-h$ incubation at $37^{\circ} \mathrm{C}$, filters were fixed and stained with Diff-Quik. Cells on the bottom side of the filters were counted in five random $\times 100$ microscope objective fields. Experiments were conducted in triplicate for each cell line.

Chemotherapy and radiation survival assays. Cells were seeded in 96-well plates at $5 \times 10^{2}$ cells per well in $100 \mu \mathrm{l}$ media, allowed to attach overnight, and treated with chemotherapy the following day (day 0 ). Chemotherapeutics included docetaxel (Sanofi-Aventis, Bridgewater, NJ, USA), cisplatin (APP Pharmaceuticals, Schaumburg, IL, USA) and vinorelbine (Bedford Laboratories, Bedford, OH, USA). All wells were replaced with fresh media after $6 \mathrm{~h}$. For radiation survival assays, tumor cells were suspended in growth media and exposed to the indicated doses of ionizing radiation using a Cs-137 irradiator, washed with media and subsequently seeded on 96-well plates. Cultures were maintained for designated times, after which cell survival was evaluated by 3-4,5-dimethylthiozol-2, 5-diphenyl-tetrazolium bromide (MTT) assay as previously described. ${ }^{7}$ Survival for treated wells was calculated as a percentage of the values representing wells of untreated cells.

Western blot and immunofluorescence. Tumor cells were lysed in RIPA (Cell Signaling Technology, Beverly, MA, USA) or SDS sample buffer; proteins $(25-60 \mu \mathrm{g})$ were resolved using $4-20 \%$ SDS-PAGE, followed by transfer to nitrocellulose membranes. The following antibodies were used: p21, cyclin D1 (Cell Signaling Technology), retinoblastoma (Thermo Fisher Scientific), Brachyury (Abcam, Cambridge, MA, USA), $\beta$-actin and GAPDH (Santa Cruz Biotechnology, Santa Cruz, CA, USA). Blots were incubated with anti-mouse or anti-rabbit IRDye secondary antibodies (LI-COR Biotechnology, Lincoln, NE, USA); specific detection was performed with the Odyssey Infrared Imaging System (LI-COR Biotechnology). Analysis of tumor cells cultured on glass cover slips was performed as previously described. ${ }^{7}$ For chemotherapy-resistant cells, A549 cells were grown to $50-60 \%$ confluency and treated for $6 \mathrm{~h}$ with cisplatin and vinorelbine (500 and $40 \mathrm{ng} / \mathrm{ml}$, respectively) or docetaxel $(1 \mathrm{ng} / \mathrm{ml})$. Surviving tumor cells were allowed to recover for 6-9 days in complete media; treatment with chemotherapeutics and subsequent recovery was repeated for three additional cycles. After the fourth cycle, cells were analyzed by immunofluorescence with the following antibodies: Brachyury (Abcam), vimentin and fibronectin (BD Biosciences).

ChIP assay. The human Brachyury ExactaChIP kit was purchased from R\&D Systems (Minneapolis, MN, USA), and used to perform ChIP analysis using H460 and A549 cells, following the manufacturer's recommendations. PCR reactions (Titanium Taq; Clontech Laboratories, Mountain View, CA, USA) were performed using primers specific for the promoter region of the human p21 gene (forward 5'-GCTCATTCTAACAGTGCTGTG-3'; reverse 5'-CAAGGAACTGACTTCGGCAG-3'); PCR products were resolved by agarose gel electrophoresis.

Luciferase reporter assay. A construct encoding the luciferase gene under the control of a 969-bp segment of the human p21 promoter was purchased from SwitchGear Genomics (Menlo Park, CA, USA). The Brachyury response element in the p21 promoter was mutated by utilizing the GENEART site-directed mutagenesis system (Invitrogen Corp.) with the following primers: forward

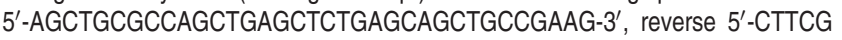
GCAGCTGCTCAGAGCTCAGCTGGCGCAGCT-3'; mutation was confirmed by sequencing. Activity was assessed by seeding tumor cells overnight in 12-well culture plates at $10^{5}$ cells per well. After overnight attachment, cells were transfected with $300 \mathrm{ng}$ of plasmid utilizing Fugene-6 (Roche Applied Science, Indianapolis, IN, USA). Renilla luciferase activity was assessed at 24-h posttransfection using Renilla-Glo (Promega, Madison, WI, USA) and a 1450 Betaplate reader (Perkin-Elmer, Waltham, MA, USA). Data were corrected by subtracting the luminescence observed in cells transfected in parallel with a control promoter reporter (SwitchGear Genomics). 
p21 induction assay. A549 pCMV and pBrachyury cells were cultured for $48 \mathrm{~h}$ in media containing $0.1 \%$ FBS to synchronize cell cycle. Tumor cells were collected and suspended in separate aliquots of media for exposure to different doses of ionizing radiation, then washed with fresh media and allowed to recover in culture for $24 \mathrm{~h}$. Asynchronous cultures of $\mathrm{H} 460$ cells were treated in a similar way. Subsequently, cell pellets were collected and lysed in SDS sample buffer and separated proteins were resolved and detected as previously described. Quantification of detected proteins was performed using Odyssey Infrared Imaging Software (LI-COR Biotechnology).

Tumor growth and immunohistochemistry. All experimental studies were carried out in accordance with the Association for Assessment and Accreditation of Laboratory Animal Care guidelines, under approval of the $\mathrm{NIH}$ Intramural Animal Care and Use Committee. To establish subcutaneous tumors, $2.5 \times 10^{6}$ tumor cells in $50 \mu$ l HBSS were suspended in an equal volume of Matrigel (BD Biosciences) then injected to flanks of 5- to 6-week-old athymic nu/nu mice; the animals were observed daily for tumor growth. When tumors became palpable, treatment of tumor-bearing mice with intraperitoneal injection of $100 \mu$ $(20 \mathrm{mg} / \mathrm{kg}$ ) docetaxel (or $100 \mu \mathrm{l} \mathrm{HBSS}$ control) every 3 days was initiated for three cycles. Tumor growth was observed and measured until euthanasia killing. Formalin-fixed, paraffin-embedded tumor sections were stained with Brachyury antibody and the Vectastain ABC kit (Vector Laboratories, Burlingame, CA, USA), then counterstained with hematoxylin. Slides were digitally scanned with an Aperio ScanScope CS scanning system (Aperio Technologies Inc., Vista, CA, USA) and analyzed by using the Aperio ImageScope Viewer software. The positive pixel count algorithm was used to measure the area and intensity of Brachyury staining. Weak-positive, positive and strong-positive staining was recorded, relative to the area evaluated.

Cell cycle analysis. Cells were harvested, fixed with ice-cold $70 \%$ ethanol for $1 \mathrm{~h}$ and stained with propidium iodide solution $(50 \mu \mathrm{g} / \mathrm{ml}$, with $100 \mu \mathrm{g} / \mathrm{ml} \mathrm{RNAse} \mathrm{A}$ for $45 \mathrm{~min}$. Peaks of stained cellular DNA were visualized using a FACSCalibur flow cytometer with CellQuest Pro software (BD Biosciences).

Statistical methods. Data were analyzed using GraphPad Prism (version 4 GraphPad Software, La Jolla, CA, USA). Two-tailed, unpaired $t$-test was used; data points in graphs represent the mean \pm S.E.M., and $P$-values $<0.05$ were considered significant

\section{Conflict of Interest}

The authors declare no conflict of interest.

Acknowledgements. We thank Dr. Jeffrey Schlom for critical review of the manuscript, Margie Duberstein for technical assistance and Debra Weingarten for editorial assistance. This research was supported by the Intramural Research Program of the Center for Cancer Research, National Cancer Institute and National Institutes of Health.

1. Edwards YH, Putt W, Lekoape KM, Stott D, Fox M, Hopkinson DA et al. The human homolog $T$ of the mouse $T$ (Brachyury) gene; gene structure, cDNA sequence, and assignment to chromosome 6q27. Genome Res 1996; 6: 226-233.

2. Kispert A, Herrmann BG. The Brachyury gene encodes a novel DNA binding protein EMBO J 1993; 12: 3211-3220.

3. Kispert A, Koschorz B, Herrmann BG. The T protein encoded by Brachyury is a tissuespecific transcription factor. EMBO J 1995; 14: 4763-4772.

4. Palena C, Polev DE, Tsang KY, Fernando RI, Litzinger M, Krukovskaya LL et al. The human T-box mesodermal transcription factor Brachyury is a candidate target for T-cellmediated cancer immunotherapy. Clin Cancer Res 2007; 13: 2471-2478.

5. Hamilton DH, Litzinger MT, Fernando RI, Huang B, Palena C. Cancer vaccines targeting the epithelial-mesenchymal transition: tissue distribution of brachyury and other drivers of the mesenchymal-like phenotype of carcinomas. Semin Oncol 2012; 39: 358-366.

6. Roselli M, Fernando RI, Guadagni F, Spila A, Alessandroni J, Palmirotta R et al. Brachyury, a driver of the epithelial-mesenchymal transition, is overexpressed in human lung tumors: an opportunity for novel interventions against lung cancer. Clin Cancer Res 2012; 18 : 3868-3879.

7. Fernando RI, Litzinger M, Trono P, Hamilton DH, Schlom J, Palena C. The T-box transcription factor Brachyury promotes epithelial-mesenchymal transition in human tumor cells. J Clin Invest 2010; 120: 533-544.
8. Fernando RI, Castillo MD, Litzinger M, Hamilton DH, Palena C. IL-8 signaling plays a critical role in the epithelial-mesenchymal transition of human carcinoma cells. Cancer Res 2011; 71: 5296-5306.

9. Savagner P. Leaving the neighborhood: molecular mechanisms involved during epithelialmesenchymal transition. Bioessays 2001; 23: 912-923.

10. Thiery JP. Epithelial-mesenchymal transitions in tumour progression. Nat Rev Cancer 2002; 2: 442-454.

11. Kalluri R, Weinberg RA. The basics of epithelial-mesenchymal transition. J Clin Invest 2009; 119: 1420-1428.

12. Nieto MA. The ins and outs of the epithelial to mesenchymal transition in health and disease. Annu Rev Cell Dev Biol 2011; 27: 347-376.

13. Hanahan D, Weinberg RA. Hallmarks of cancer: the next generation. Cell 2011; 144: 646-674.

14. Yang AD, Fan F, Camp ER, van Buren G, Liu W, Somcio R et al. Chronic oxaliplatin resistance induces epithelial-to-mesenchymal transition in colorectal cancer cell lines. Clin Cancer Res 2006; 12: 4147-4153.

15. Kajiyama H, Shibata K, Terauchi M, Yamashita M, Ino K, Nawa A et al. Chemoresistance to paclitaxel induces epithelial-mesenchymal transition and enhances metastatic potential for epithelial ovarian carcinoma cells. Int J Oncol 2007; 31: 277-283.

16. Arumugam T, Ramachandran V, Fournier KF, Wang H, Marquis L, Abbruzzese $\mathrm{JL}$ et al. Epithelial to mesenchymal transition contributes to drug resistance in pancreatic cancer. Cancer Res 2009; 69: 5820-5828.

17. Vega S, Morales AV, Ocana OH, Valdes F, Fabregat I, Nieto MA. Snail blocks the cell cycle and confers resistance to cell death. Genes Dev 2004; 18: 1131-1143.

18. Gupta PB, Onder TT, Jiang G, Tao K, Kuperwasser C, Weinberg RA et al. Identification of selective inhibitors of cancer stem cells by high-throughput screening. Cell2009; 138: 645-659.

19. Liu M, Casimiro MC, Wang C, Shirley LA, Jiao X, Katiyar S et al. p21CIP1 attenuates Rasand c-Myc-dependent breast tumor epithelial mesenchymal transition and cancer stem cell-like gene expression in vivo. Proc Natl Acad Sci USA 2009; 106: 19035-19039.

20. Baker SD, Zhao M, Lee CK, Verweij J, Zabelina Y, Brahmer JR et al. Comparative pharmacokinetics of weekly and every-three-weeks docetaxel. Clin Cancer Res 2004; 10: 1976-1983.

21. Ikeda K, Terashima M, Kawamura H, Takiyama I, Koeda K, Takagane A et al. Pharmacokinetics of cisplatin in combined cisplatin and 5-fluorouracil therapy: a comparative study of three different schedules of cisplatin administration. Jpn J Clin Oncol 1998; 28: 168-175.

22. Leveque D, Jehl F, Quoix E, Breillout F. Clinical pharmacokinetics of vinorelbine alone and combined with cisplatin. J Clin Pharmacol 1992; 32: 1096-1098.

23. Qiao X, Tullgren O, Lax I, Sirzen F, Lewensohn R. The role of radiotherapy in treatment of stage I non-small cell lung cancer. Lung Cancer (Amsterdam, The Netherlands) 2003; 41: 1-11.

24. Harper JW, Adami GR, Wei N, Keyomarsi K, Elledge SJ. The p21 Cdk-interacting protein Cip1 is a potent inhibitor of G1 cyclin-dependent kinases. Cell 1993; 75: 805-816.

25. LaBaer J, Garrett MD, Stevenson LF, Slingerland JM, Sandhu C, Chou HS et al. New functional activities for the p21 family of CDK inhibitors. Genes Dev 1997; 11: 847-862.

26. Kispert A, Herrmann BG, Leptin M, Reuter R. Homologs of the mouse Brachyury gene are involved in the specification of posterior terminal structures in Drosophila, Tribolium, and Locusta. Genes Dev 1994; 8: 2137-2150.

27. Behr R, Heneweer C, Viebahn C, Denker HW, Thie M. Epithelial-mesenchymal transition in colonies of rhesus monkey embryonic stem cells: a model for processes involved in gastrulation. Stem Cells 2005; 23: 805-816.

28. Vidricaire G, Jardine K, McBurney MW. Expression of the Brachyury gene during mesoderm development in differentiating embryonal carcinoma cell cultures. Development 1994; 120: 115-122.

29. Palena C, Fernando RI, Litzinger MT, Hamilton DH, Huang B, Schlom J. Strategies to target molecules that control the acquisition of a mesenchymal-like phenotype by carcinoma cells. Exp Biol Med (Maywood) 2011; 236: 537-545

30. Kurrey NK, Jalgaonkar SP, Joglekar AV, Ghanate AD, Chaskar PD, Doiphode RY et al. Snail and slug mediate radioresistance and chemoresistance by antagonizing p53-mediated apoptosis and acquiring a stem-like phenotype in ovarian cancer cells. Stem Cells 2009; 27: 2059-2068.

31. Viebahn C, Stortz C, Mitchell SA, Blum M. Low proliferative and high migratory activity in the area of Brachyury expressing mesoderm progenitor cells in the gastrulating rabbit embryo. Development 2002; 129: 2355-2365.

32. Stuart-Harris R, Caldas C, Pinder SE, Pharoah P. Proliferation markers and survival in early breast cancer: a systematic review and meta-analysis of 85 studies in 32,825 patients. Breast 2008; 17: 323-334

33. Wang W, Goswami S, Lapidus K, Wells AL, Wyckoff JB, Sahai E et al. Identification and testing of a gene expression signature of invasive carcinoma cells within primary mammary tumors. Cancer Res 2004; 64: 8585-8594.

34. Mejlvang J, Kriajevska M, Vandewalle C, Chernova T, Sayan AE, Berx G et al. Direct repression of cyclin D1 by SIP1 attenuates cell cycle progression in cells undergoing an epithelial mesenchymal transition. Mol Biol Cell 2007; 18: 4615-4624.

35. Noseda M, Chang L, McLean G, Grim JE, Clurman BE, Smith LL et al. Notch activation induces endothelial cell cycle arrest and participates in contact inhibition: role of p21Cip1 repression. Mol Cell Biol 2004; 24: 8813-8822.

36. Waldman T, Kinzler KW, Vogelstein B. p21 is necessary for the p53-mediated G1 arrest in human cancer cells. Cancer Res 1995; 55: 5187-5190. 
37. Brown JP, Wei W, Sedivy JM. Bypass of senescence after disruption of p21CIP1/WAF1 gene in normal diploid human fibroblasts. Science 1997; 277: 831-834.

38. Brugarolas J, Chandrasekaran C, Gordon JI, Beach D, Jacks T, Hannon GJ. Radiationinduced cell cycle arrest compromised by p21 deficiency. Nature 1995; 377: 552-557.

39. Mani SA, Guo W, Liao MJ, Eaton EN, Ayyanan A, Zhou AY et al. The epithelialmesenchymal transition generates cells with properties of stem cells. Cell 2008; 133 704-715.

40. Polyak K, Weinberg RA. Transitions between epithelial and mesenchymal states: acquisition of malignant and stem cell traits. Nat Rev Cancer 2009; 9: 265-273.

41. Du Z, Qin R, Wei C, Wang M, Shi C, Tian R et al. Pancreatic cancer cells resistant to chemoradiotherapy rich in 'stem-cell-like' tumor cells. Dig Dis Sci 2011; 56: 741-750.
42. Sarkar D, Shields B, Davies ML, Muller J, Wakeman JA. BRACHYURY confers cancer stem cell characteristics on colorectal cancer cells. Int $J$ Cancer 2011; 130: 328-337.

(c) $(\$)$ Cell Death and Disease is an open-access journal published by Nature Publishing Group. This work is licensed under a Creative Commons Attribution-NonCommercialNoDerivs 3.0 Unported License. To view a copy of this license, visit http://creativecommons.org/licenses/by-nc-nd/3.0/ 